\title{
La escritura que lee a la escritura: José Ángel Valente, traductor. Algunas calas
}

\author{
Writing Reading Writing: \\ José Ángel Valente as Translator. Some Cases
}

\author{
Juan Manuel del Río Surribas \\ IES A Pobra do Caramiñal
}

\section{RESUMEN}

José Ángel Valente, poeta bilingüe y traductor profesional en diferentes instituciones internacionales, frecuentó además de la creación poética y prosística la reescritura de textos ajenos procedentes de lenguas extranjeras. Su labor como traductor o versionador quedó recogida tras su muerte en el volumen Cuaderno de versiones. El presente estudio expone la concepción de traducción en José Ángel Valente en relación con una serie de nociones clave en su pensamiento estético y con su propia obra. Además, analiza un conjunto de ejemplos de su labor como traductor comparándolos con su original en los que se muestra cómo el proceso de traducción implica un proceso de reescritura creativa. A la luz de este análisis, plantea la consideración en pie de igualdad de su faceta de escritor y traductor, y la condición de creación literaria de esta última.

Palabras Clave: José Ángel Valente; poesía contemporánea; traducción; teoría literaria.

\begin{abstract}
Besides poetic and prose writings, José Ángel Valente, bilingual poet and professional translator in many international institutions, practiced also the rewording of other people's texts written in foreign languages. His works as translator or versionador were collected, after his decease, in the volume Cuaderno de versiones. This paper exposes Valente's translating idea in relationship with any key notions in his aesthetic thought and with his own works. Also, it analyzes a group of examples of his labour as translator comparing these texts with their original version. That essay shows how translating supposes a new writing creative process. Taking this into consideration, we propose to give the same relevance to his production as a writer and as a translator, and to consider this last one as literary creation.
\end{abstract}

Key words: José Ángel Valente; Contemporary poetry; Translation; Literary theory. 
Antes de entrar de lleno en la reflexión sobre la visión valenteana de la traducción literaria sería necesario realizar un somero repaso de aspectos biográficos del autor gallego relacionados con su identidad lingüística y su conocimiento de lenguas extranjeras.

Para el tema que nos atañe conviene recordar dos consideraciones. Por un lado, Valente se cría en un contexto sociocultural asimétricamente bilingüe: aunque la lengua familiar sea el castellano y reciba una formación escolar exclusivamente en esta lengua, su contacto con la lengua gallega es también directo, pues lo oye hablar a personas de su entorno. El carácter diglósico del contexto lingüístico en el que se forma lo convierte en castellano-hablante aunque, por la empatía que siente hacia el gallego como lengua maltratada, desea evolucionar hacia el bilingüismo ${ }^{1}$. Por otro lado, las diferentes residencias en ciudades europeas -Oxford (1954-1958), Ginebra y Collonges-sousSalève (1958-1981) y, finalmente, París (1981-1985)² - le permiten realizar una prolongada y profunda inmersión en las culturas y las lenguas inglesa y francesa. Asimismo, el cargo que asume en los destinos suizo y francés, como traductor de la OMS y de la UNESCO, lo ponen en contacto con las dos otras grandes lenguas europeas, el italiano y el alemán, puerta de acceso a la lectura directa de sus literaturas ${ }^{3}$. Puede afirmarse, por tanto, que el autor de Cuaderno de versiones es, por origen, hablante y creador bilingüe y que las circunstancias vitales y laborales lo han hecho capacitado lector plurilingüe.

\section{LA CONCEPCIÓN POÉTICA DE LA TRADUCCIÓN EN JOSÉ ÁNGEL VALENTE}

\subsection{Noción de traducción y estética de la anonimia}

El poeta ourensano afirma en Notas de un simulador:

CUANDO ESCRIBO la palabra yo en un texto poético o este va, simplemente, regido por la primera persona del singular, sé que, en ese preciso momento, otro ha empezado a existir. Por eso, muchas veces, al yo del texto es preferible llamarle tú.

Ese yo - que es tú porque también me habla - no existe antes de iniciarse el acto de escritura. Es estrictamente contemporáneo de éste (Valente, 2008: 465).

\footnotetext{
${ }^{1}$ Así lo refiere en una entrevista concedida a Ana Romaní: «(...) eu sentín a necesidade de escribir en galego, quizais porque cando era moi novo o galego estaba prohibido (...). Entón eu, que era dunha familia de dereitas, pois sentín iso como unha afrenta e comecei a escribir en galego moi pronto» (Romaní, 2001: 423).

${ }^{2}$ Cfr. Sánchez Robayna (2006: 41).

3 No obstante, como se comprueba al observar la datación que ofrece Rodríguez Fer (2002) de las versiones de Valente es el contacto directo con las lenguas, que le aporta seguridad al usarlas, lo que lo motiva a realizar las traducciones literarias y no tanto la profesión ejercida (pues, efectivamente, los periodos de traducción literaria son más productivos antes y después de su carrera profesional como traductor).
} 
Ubicar la enunciación en la perspectiva interna del sujeto enunciador, vehiculada lingüísticamente a través de la marca de primera persona, debería abocar al texto a una dirección autoenunciadora con posibles funciones comunicativas de una experiencia determinada o autoexplorativas de la identidad. Ahora bien, como Valente vislumbra, en ese proceso de traducir a un código verbal los pensamientos del poeta, la identidad física de este no consigue pasar el tamiz verbal: queda fuera de la escritura y su lugar lo ocupa un nuevo sujeto de naturaleza verbal, ese yo-otro del texto contemporáneo al momento de escritura y cuya existencia queda reducida a la realidad del texto. Aunque reducido, a causa del vacío dejado por el yo físico autorial, ese yo-otro textual se adueña, en la transferencia operada en la escritura, de todo el territorio del texto y se convierte en su único poblador. Asumida esa posición dominante del yo textual, solo le queda al yo autorial adoptar en el juego de funciones textuales la de escucha: oír lo que ese yo-otro «me habla».

Se deduce de ello que el poeta no puede asumir una actitud rectora en la experiencia poética, sino una función intermedia: ser lugar para que la palabra se revele. El poeta debe aceptar su función como lugar propiciatorio para la aparición de la palabra, y ahí radicaría la verdadera labor del poeta: no se trata tanto de dirigir el discurso poético como de desplazar el centro identitario hacia fuera, engendrando un vacío que libera de todo condicionamiento autorial a la palabra poética.

De esta concepción valenteana se derivan dos nociones que conviene tener presente por su importante relación con el concepto de traducción: por una parte, la consideración de la palabra poética como palabra descondicionada de la intención del autor; por otra parte, la negación de la conexión entre autoría textual y yo enunciativo que deriva en la experiencia de la otredad.

La visión del fenómeno poético como acto de encarnación de la palabra en el poeta (el poeta como espacio en el que se revela la palabra poética) deviene estética de la anonimia. Puesto que lo poético solo se manifiesta en la ausencia del yo autorial y puesto que, derivado de esto, la palabra se materializa desde la desvinculación con la identidad del sujeto, carece de importancia, desde el punto de vista de la creación poética, la marca de autoría, dado que yo y otro viven en la indistinción anónima que genera la palabra poética en el cuerpo del ser. Dicho de otro modo, la importancia de la palabra manifestada borra el valor del autor por medio del cual se ha materializado. En este sentido, creación y traducción no se distinguen en cuanto escrituras, pues en ambos casos lo poético no reside en el autor (o el traductor) sino en la palabra que se encarna en ellos. Y, del mismo modo, autor y traductor anhelan lo mismo: ser medio a través del cual la palabra se haga manifestación verbal. En el contacto radical con la palabra no hay más agente gestador que la palabra misma y, por eso, el anclaje del sujeto (sea el yo, sea el otro) desaparece: la palabra descondiciona la autoría de quien habla y esa es una experien- 
cia que viven tanto autor como traductor en la escritura. Así pues, José Ángel Valente no concibe el ejercicio de traducción como una escritura subsidiaria o secundaria con respecto a la escritura poética, sino como un ejercicio de similar naturaleza y proceso que el de la creación. Aunque por un camino distinto, el autor gallego coincide, de este modo, con la tesis de Octavio Paz, «Traducción y creación son operaciones gemelas» (1990: 23). Así, afirma en una entrevista sobre la tarea de la traducción:

Lo que yo he escrito lo siento tan escrito por mí como lo que he traducido de un poeta inglés o alemán (Pérez-Ugena, 1999: 56).

\subsection{Traducción y creación poética}

Al igual que Octavio Paz, Valente no alberga ningún prejuicio estético negativo acerca de la traducción como escritura y afirma, con el autor mexicano, que la traducción nunca puede ser literal ${ }^{4}$, sino reescritura del texto original. Por esta razón, opta por no referirse a sus traducciones literarias como tales, pues el término es ambiguo y puede interpretarse como trasposición literal a otra lengua ${ }^{5}, y$, así, prefiera utilizar el más marcado término de versión que emplea el propio autor en los preliminares que preceden a su traducción de textos de Cavafis y de Paul Celan (Valente, 2002: 153 y 233). Manuel Fernández Rodríguez realiza una interesante precisión terminológica a este respecto: quizá debiera hablarse de apropiación o versión cuando nos referimos al proceso creativo o re-creativo y emplear el término de traducción cuando se alude a la dimensión social de translación literaria (2006: 14).

Como bien señala Claudio Rodríguez Fer en la introducción a la edición recopilatoria de las traducciones valenteanas, la escritura de creación y la traducción confluyen a lo largo de su obra y se nutren mutuamente. Como es sabido, muchos de sus textos cobran sentido completo en su condición de intertexto que remite a la lectura de una obra de otro autor ${ }^{6}$. En otros momen-

\footnotetext{
${ }^{4}$ «No digo que la traducción literal sea imposible, sino que no es una traducción» (Paz, 1990: 13).

${ }^{5}$ No descartamos, por otro lado, que otra razón sea que asociase el término traducción a su labor profesional en la OMS y la UNESCO.

${ }^{6}$ Rodríguez Fer señala varios casos a lo largo de la trayectoria del poeta ourensano: «John Cornford, 1936», de La memoria y los signos (1966), remite a dos citas del británico Auden; «Maquiavelo en San Casciano», a una carta de Maquiavelo dirigida a Vettori; «La poesía», de Breve son (1968), a versos de Rosalía de Castro que son, a su vez, paráfrasis de un poema popular gallego; «Segundo homenaje a Isidore Ducasse», del mismo libro, a un fragmento de Poésies II de Lautréamont; «Anales de Volusio», de El inocente (1970), al famoso poema de Catulo; y la Odisea de Homero es referente claro en «Reaparición de lo heroico», de El inocente, y de «Rapsodia vigésimosegunda», de El fin de la edad de plata (1973). A estos casos hay que sumar, aquellos textos en los que se cita la fuente de modo
} 
tos, el recurso puntual de la intertextualidad se convierte en proceso de creación por sí mismo y el texto original es apropiado, esto es, hecho propio, por Valente ${ }^{7}$.

Como quedó dicho con anterioridad, el autor ourensano asumió la escritura de traducción como tarea de creación propia y recibió un tratamiento editorial en pie de igualdad con respecto a su producción poética, narrativa y ensayista, pues Valente dejó encargada la tarea editorial de recopilar y publicar todas sus traducciones en un volumen que salió dos años después de su muerte bajo el significativo título de Cuaderno de versiones. Dicho estatus editorial de esta producción fue, más tarde, mantenido en la recopilación que de las obras completas realizó la editorial Galaxia Gutenberg/Círculo de Lectores y así aparece recogida en el primer volumen de sus obras completas, dedicado a la poesía y a la prosa de creación, tras los poemarios de producción propia.

A esto podemos añadir además el hecho nada desdeñable de que fue una actividad que desarrolló de forma paralela a la de su poesía. Traduce a Dylan Thomas, Eugenio Montale y Gerald Manley Hopkins en fechas que coinciden con el proceso creativo que dio lugar a la aparición de sus dos primeros poemarios; se dedica a la traducción de Cavafis entre 1962 y 1973 y a la de Keats, Louis Aragon, Péret y Cioran coincidiendo con la aparición de los últimos poemarios del ciclo de Punto cero. Y en paralelo con la evolución de su producción poética última, desarrolla la labor de versión de la obra de Paul Celan. En ese periodo y coincidiendo con su jubilación como traductor oficial de la UNESCO, es justamente cuando se concentran y diversifican los intereses traductores de José Ángel Valente, pues desde 1985 versiona a Robert Duncan, Edmond Jabès, Marcel Cohen, Friedrich Hölderlin, Paul Celan e, incluso, el prólogo del Evangelio de San Juan.

Por otro lado, el hecho de que casi todos los autores escogidos sean figuras de preferencia del poeta gallego da nuevo testimonio de la imbricación de

directo, ya sea en su forma original (como sucede, por diferente motivo, con el cantautor Claude McKay y con Hitler, en Presentación y memorial para un monumento), ya sea en traducción castellana (en Notas de un simulador se convierten en texto valenteano fragmentos citados de Lec, Eliot, Tsetáiev, Celan, Hölderlin, Drumond de Andrade, etc.). Vid. Rodríguez Fer (2002: 7-9).

${ }^{7}$ Por ejemplo, en El inocente (1970) se recoge el poema titulado «Crónica II, 1968», que es traducción de un fragmento de Le Pèse-Nerfs, de Antonin Artaud (Rodríguez Fer, 2002: 8), así como en Mandorla (1982) el poema «Versión de Trakl-Webern» es versión en castellano de «Die Sonne» del poeta austríaco. Pero, es sobre todo en Fragmentos de un libro futuro donde la apropiación se vuelve proceso creativo recurrente y, así, las versiones que escribe Valente de poemas de otros autores son considerados por éste como creaciones propias. De este modo, las versiones de textos, en su mayoría orientales, que aparecen en este libro son lecturas que Valente hace del sentido que estos ofrecen y que, por medio de la trasposición libre al castellano, reescribe para convertirlos, en dicho proceso de traducción, en recreación, esto es, en nueva creación poética. 
esta faceta valenteana con la creación poética ${ }^{8}$. Así, referentes reconocidos por el propio poeta y señalados por la crítica como influencias destacadas en su obra (tales como Eugenio Montale, Edmond Jabès y, sobre todo, Paul Celan) se destacan en este corpus de traducciones ${ }^{9}$. Del mismo modo, gran número de textos versionados desarrollan ideas o motivos recurrentes en la poesía de Valente, hasta el punto de que, en ocasiones, es muy sutil el límite que separa la consideración de unos textos como creación y otros como versión. Tal es el caso de «Versión de Trakl-Webern», recogido en Mandorla, (considerado como poema propio) y la traducción del poema homónimo de Paul Celan, de la que precisamente toma nombre el poemario (considerado como versión).

\subsection{Traducción y fidelidad lingüística}

Ya fue señalado que de la derivación de esa estética de la anonimia y de la consideración del descondicionamiento de la palabra poética deviene, en Valente, una noción de la traducción que, en términos lingüísticos, implica que el compromiso de escritura es más con el poema y con la experiencia poética presente en él que con la voluntad original del autor o con el texto en tanto que producto lingüístico. Esto queda demostrado por el hecho de que en varias ocasiones el autor de Cuaderno de versiones acepta la intervención de un tercero en el proceso de reescritura del texto original. Tales son los casos de las versiones de los poemas de Dylan Thomas y Robert Duncan (en colaboración con los profesores W. Gordon Chapman y Julian Palley, respectivamente), las traducciones desde una lengua intermedia de Günter Kunert, Che-LanVien, Ludwig Hohl o Yehuda Amichi y, sobre todo, las versiones de Cavafis ${ }^{10}$.

\footnotetext{
${ }^{8}$ Como señala Fernández Rodríguez «previo a esa traducción, existe un movemento de aproximación e de identificación do poeta-tradutor co poeta-traducido, motivo polo que, necesariamente, debemos falar de equivalencias expresivas, conceptuais e, esencialmente, poéticas entre Valente e os diversos poetas obxecto da súa atención» (2006: 13).

${ }^{9}$ Fernández Rodríguez va más allá y señala en la elección de los autores se representa una suerte de disidencia y beligerancia ideológica y poética radical y extrema, que se manifiesta en el modo en que interactúa con las fuentes escogidas (2006:15). Y, unas páginas más adelante, incide en el hecho paradójico de que, a pesar de la diversidad de autores y contextos histórico-literarios representados en Cuadernos de versiones, se observa una unidad de sentido no solo con respecto a los textos escogidos entre sí sino con respecto al universo literario valenteano.

${ }^{10}$ Como el presente estudio se centra en el análisis comparado de las versiones valenteanas con su original para observar las elecciones lingüísticas y reflexionar sobre la condición creativa de esta reescritura, queda este corpus fuera de nuestro análisis al difuminarse en todas ellas la reescritura valenteana por la intervención de terceras personas. A ello se suma, en el caso de Cavafis, que nuestro desconocimiento de la lengua griega nos impide analizar el proceso de trasvase al castellano $\mathrm{y}$, por tanto, valorar cuánto de reescritura hay en la versión.
} 
En el caso de la traducción de Cavafis, autor del que realizó mayor número de versiones, recurrió a la ayuda de Elena Vidal, cuya implicación en la traducción queda descrita de modo plástico por Valente en el prólogo a las versiones:

[...] mi colaboradora y amiga Elena Vidal produjo una primera traducción e interpretación de los originales seleccionados. En la última fase de nuestro trabajo, el texto preparado por el autor de estas líneas fue sometido en común a nueva crítica y definitiva confrontación con el original (Valente, 2002: 153-154).

De estas palabras podemos extraer dos conclusiones relevantes acerca de la concepción valenteana de la traducción. La primera es que no se ve mediatizado u obsesionado por la exactitud o precisión de la traducción, es decir, por la fidelidad lingüística al texto original (si fuera así, no admitiría crear su traducción a partir de un texto que no fuera el original). La segunda conclusión es que, no obstante esto, Valente trata de evitar en la medida de lo posible que cualquier error lingüístico en el proceso de trasposición afecte negativamente no tanto a la lengua del texto como al espíritu del mismo. He ahí la importancia que pone en una revisión crítica de su versión ${ }^{11}$.

\section{LA TRADUCCIÓN COMO REESCRITURA SOBRESIGNIFICATIVA: «IL TUFFATO- RE» DE MonTALE Y VALENTE}

La primera versión poética firmada en exclusividad ${ }^{12}$ por él fue del poema «Incontro» de Eugenio Montale, según informa Claudio Rodríguez Fer (2002: 16). La vinculación del autor ourensano con el italiano se cifra, podemos afirmar con Manuel Fernández Rodríguez, en un movimiento de aproximación e identificación asentado en una participación común de intereses que va más allá de la traducción puntual (2004: 82). Dicha identificación queda expresada con claridad en la selección de textos que escoge versionar. Como señala este crítico, la visión del mundo que arroja el poema «Encuentro», con sus referentes memorísticos que constatan el paso del tiempo y la inconsistencia de la vida humana, apunta a un existencialismo esencial en la línea del

${ }^{11}$ Sobre la calidad poética de la traducción valenteana de Cavafis tal vez baste con recuperar las palabras dedicadas por Gimferrer en las que, además de incidir en la fidelidad al original, señala que el «eco sustancialmente uno de la obra llega igualmente al lector» y apuntar los aciertos poéticos de la versión, afirma: «traducido por Valente, Cavafis nos remite a Valente», apostillando a continuación «como debía ser» (1964: 3).

Similar valoración positiva sostiene Vicente Fernández González (2001), quien en diferentes lugares de su estudio de las traducciones al castellano de Cavafis incide en la calidad literaria de la versión valenteana.

${ }^{12}$ Anterior había sido la del poema de Dylan Thomas, pero esta había sido firmada por W. Gordon Chapman. 
Valente de Punto cero. Del mismo modo, la temática metapoética en «La forma del mundo» entronca a la perfección con el pensamiento del autor gallego y «El arte pobre» da entrada a la reflexión sobre la cuestión interartística y a la poética del resto, motivos muy próximos a la sensibilidad del autor de Elogio del calígrafo (Fernández Rodríguez, 2004: 82-84). Otro tanto podría decirse al respecto de «El Rey pescador», «El lago de Annecy», «Carta a Boby» o «El olor de la herejía». No obstante, querríamos centrar nuestro análisis en lo que sucede con el poema que Montale titula en honor a la famosa losa funeraria hallada en Paestum «Il tuffatore», único texto que presenta la singular condición de haber dado lugar a una versión y a un nuevo poema valenteanos ${ }^{13}$.

La transliteración del poema montaliano ha sido ya analizada desde el punto de vista lingüístico por Pérez-Ugena (2003: 673). Sobre la versión, afirma este autor, «Valente intenta respetar el poema original», si bien presenta algunas soluciones que se alejan del original. Es el caso de: la palabra tuffatore, de cuya complicada equivalencia evocadora en castellano da cuenta Pérez-Ugena (2003: 674); de ragniforme en el verso 2 (que el ourensano traduce por «filiforme» en lugar del más exacto 'aracniforme'), de scalleta en el verso 6 («escala», en la versión valenteana, en lugar de 'escalera', por la resonancia deportiva y el eco bíblico, según Pérez-Ugena, 2003: 673); o de buio en el penúltimo verso («sombra», escogido por el escritor gallego, apunta Pérez-Ugena, por razones métricas y por la remisión a un afamado verso virgiliano). Todas estas variaciones con respecto a la traducción literal nos hacen percibir en Valente un ejercicio estilístico de búsqueda de la expresión que o bien no dañe el ritmo de la versión castellana o bien ofrezca ecos intertextuales que restauren el espíritu del poema y de la pintura funeraria que motiva la escritura del poema montaliano. Esto es, nuestro autor asume como necesario a la reescritura que entraña la traducción poética el renunciar a la exactitud lingüística en favor de la precisión poética, hecho que vendría a confirmar lo anteriormente apuntado sobre la fidelidad al texto original en la tarea de traducción.

No obstante, si por algo resulta significativo la traducción de «Il tuffatore» es por haber sido un paso intermedio necesario, así lo percibimos, para la recreación poética que da lugar al poema homónimo de Valente, publicado en 1982 en el libro Mandorla:

\section{Il Tuffatore}

No estamos en la superficie más que para hacer una inspiración profunda que nos permita regresar al fondo. Nostalgia de las branquias (Valente, 2006: 424).

\footnotetext{
${ }^{13} \mathrm{Si}$ bien es cierto que el poema «Mandorla» de Paul Celan da lugar a una versión en castellano y, posteriormente, da título a un poema (y poemario) de título homónimo, no se produce, como en el caso de «Il tuffatore», un diálogo tan cómplice entre la lectura del poema valenteano y la del hipotexto.
} 
Nada en el poema remite de modo directo al texto montaliano, salvo el título en italiano ${ }^{14}$. Sin embargo, es este el que significativamente, al remitir al poema italiano y a la losa funeraria encontrada en Paestum, ofrece la posibilidad de comprender la escena atrayendo a la superficie textual el hipotexto que motiva la escritura y sobredota de significado poético el poema valenteano al entablar una red de relaciones culturales que teje con dichos referentes. Valente se apropia de la escena pictórica de la losa funeraria y de modo paradójico, escondiendo el discurso ecfrástico de la pieza en el cuerpo del texto, focaliza la atención poética en la imagen, de modo que se potencia la lectura alegórica de la escena (recuperando el sentido original de alegoría del tránsito de la vida a la muerte) y la resignifica como un poema de raíz poéticamente valenteana ${ }^{15}$. De hecho, la interactuación de este poema con los demás textos que lo preceden en la sección III de Mandorla habilita la interpretación de la imagen del nadador en clave metaliteraria. Es decir, la voluntad con que dispone el poema en ese lugar del libro busca que «Il tuffatore» sea interpretado como un poema-poética, de modo que la aparición e inmediata inmersión del nadador remitan a otros fragmentos de la obra del autor ourensano, tales como: «La forma en su plenitud apunta infinitamente hacia lo informe» (Valente, 2008: 422), de «Sobre la lengua de los pájaros»; o «la palabra poética se sustancia entre el entender y lo inteligible, entre el decir y lo indecible, entre la extinción de la imagen y la plenitud de la visión» (Valente, 2008: 310), del ensayo «Juan de la Cruz, el humilde del sin sentido».

Al igual que sucede, como se verá en el apartado siguiente, en el caso de «Versión de Trakl-Webern», el poema de Mandorla se convierte en un texto que, motivado en buena medida por el proceso de reescritura que supuso la versión de 1975, ve potenciada la multiplicidad de sentidos que se van incorporando con cada versión añadida a la intrahistoria del tuffatore de Paestum: a la sugestiva lectura iconográfica, cultural y contextual de la pintura funeraria hallada por Mario Napoli en 1968, se le van superponiendo sucesivamente la recreación ecfrástica de Montale en 1973, su versión castellana de 1975 y la lectura condensada y reapropiadora del poema valenteano de 1982.

${ }^{14}$ A este respecto, Pérez-Ugena afirma que tal elección se justifica no solo por «la fama de la pintura, sino por la intraducibilidad, por su belleza superior» (2003: 674). Si bien compartimos la primera razón, nos resulta discutible la segunda. De hecho, cuando Valente realiza la versión castellana no tiene ningún inconveniente en eliminar el título cuando precisamente sería francamente factible o esperable que se mantuviese. Por ello, creemos que la opción valenteana de 1982 tiene una razón más sencilla, que profundiza en la primera justificación apuntada por Pérez-Ugena: el título en italiano permite al lector relacionar el poema valenteano con la pintura funeraria $\mathrm{y}$, sobre todo, con el poema montaliano.

${ }^{15}$ Remiten a la poética del autor gallego la imagen de la vida como un lapsus o instante de suspensión del tiempo de la muerte y la concepción de que no son los vivos los que olvidan a los muertos sino que son los muertos los que olvidan a los vivos (Pérez-Ugena, 2003: 676). 


\section{LA TRADUCCIÓN COMO APROPIACIÓN: «VERSIÓN DE TRAKL-WEBERN»}

Como ya fue apuntado con anterioridad, el escritor ourensano incorpora a la parte IV de Mandorla un texto ${ }^{16}$ que es en esencia trasposición al castellano del «Die Sonne» ${ }^{17}$ del poeta austríaco Georg Trakl.

A excepción del cambio de título (por «Versión de Trakl-Webern»), la cita inicial («Para voz y cuatro instrumentos») y la división estrófica —que más adelante serán comentadas-, la traducción es desde un punto de vista lingüístico impecable, precisa y fiel al texto de Trakl tanto a nivel léxico como gramatical. No obstante, hay una serie de lugares en donde la versión se desvía de la fidelidad textual sin que, en ningún caso, se pueda afirmar que la opción tomada por Valente no se ajuste al sentido original.

En el verso 1 se traduce «kommen (...) über» por 'asomar... en'. La traducción literal implicaría la siguiente versión: «Diario se aproxima el dorado sol por encima de la colina». Esta elección, como es palpable, supondría recargar innecesariamente el verso de Trakl, prosificarlo; problema fácilmente subsanable si se condensan los contenidos de movimiento y posición en la solución valenteana «asomar en», que, además, expresa con gran plasticidad visual la trayectoria del sol al amanecer. Esta plasticidad casi pictórica se ve, por otro lado, reforzada al sustituir el adjetivo calificativo gelbe — 'dorado' o 'de oro' - por el sustantivo «amarillo» que carga el valor de la voz en su sentido cromático, muy acorde con el carácter del texto original, donde tiene gran importancia el color. Y algo similar ocurre en el verso 6, donde se lee la expresión «Fährt... leise» ${ }^{18}$. La calificación semántica que leise proyecta sobre el movimiento que expresa el verbo fahren - 'conducir(se) sin hacer ruido, de modo suave' - tiene en la elección valenteana — «deslizar»— su traducción más exacta y adecuada desde el punto de vista lingüístico y una opción poéticamente de gran plasticidad y fuerza sugestiva.

${ }^{16}$ Reproducimos a continuación el poema valenteano:

Diario asoma el amarillo en la colina. // Bello es el bosque, el oscuro animal, el hombre, / cazador o pastor. // Rojo se eleva en el estanque verde el pez. // Bajo el redondo cielo el pescador desliza / su barca azul. // Maduran lentos la uva, el grano. // Al extinguirse quietamente el día / el bien y el mal ya son. // Cuando cae la noche, el caminante / alza despacio sus pesados párpados. // Rompe desde un sombrío abismo el sol (Valente, 2006: 435).

${ }^{17}$ Reproducimos aquí el texto original:

Täglich kommt die gelbe Sonne über den Hügel. / Schön ist der Wald, das dunkle Tier, / Der Mensch; Jäger oder Hirt. // Rötlich steigt im grünen Weiher der Fisch. / Unter dem runden Himmel / Fährt der Fischer leise im blauen Kahn. // Langsam reift die Traube, das Korn. / Wenn sich stille der Tag neigt, / Ist ein Gutes und Böses bereitet. // Wenn es Nacht wird, / Hebt der Wanderer leise die schweren Lider; / Sonne aus finsterer Schlucht bricht.

${ }^{18}$ La forma verbal fahren se emplea en alemán para indicar un desplazamiento no realizado a pie y leise es adjetivo que significa 'silencioso, ligero, suave, delicado'. 
El verso 9 dice, en el original de Trakl, «Ist ein Gutes und Böses bereitet» —literalmente «un bien y mal está hecho»—, que Valente traduce como «el bien y el mal ya son». Es, sin duda, el verso en que se establece una distinción más clara entre la traducción literal y la versión valenteana, aunque, como en los anteriores casos, el sentido de la imagen permanezca intacto. La diferencia radica en la lectura que prioriza el autor gallego. Bereiten en alemán significa 'hacer', 'preparar' y Trakl conjuga esta forma verbal empleando una variante de la construcción pasiva ${ }^{19}$. Valente demuestra aquí conocer muy bien la gramática alemana y, por eso, elige el verbo ser — que remite al sentido de esencia como existencia, nacimiento del ser- acompañado de un adverbio temporal $y a$, inexistente en el original pero que contribuye a incidir en la condición perfectiva de la imagen. De este modo, en la solución escogida por el autor de Cuaderno de versiones perviven los matices del verbo alemán bereiten (acción) y de la construcción gramatical (resultado del proceso). Por otro lado y en concordancia con la lectura que realiza del texto de Trakl, Valente opta por el artículo el, en lugar del indeterminado ein que emplea el austríaco, para reforzar el sentido filosófico de la visión del anochecer.

En el siguiente verso del original («Wenn es Nacht wird») vuelve a aparecer el verbo werden, ya como verbo principal $^{20}$. Puesto que aquí hace referencia al paso del día a la noche como consecuencia de la desaparición en movimiento descendente del sol, Valente decide traducir werden por un rotundo «caer», traducción fiel no del verbo pero sí de la imagen, que incide en lo abrupto del cambio.

Por otra parte, desde el punto de vista sintáctico del orden de las palabras, lo esperable, dado que alemán y castellano poseen organizaciones sintácticas que se rigen por leyes distintas, sería que el escritor ourensano no siguiese el modelo original. Sin embargo, la simplicidad sintáctica del texto de Trakl le permite calcar la disposición de las palabras en casi todo momento. Solo en el verso 8 hay una leve variación. El texto de Trakl construye una oración subordinada temporal cuyo nexo wenn introduce una predicación sobre la forma verbal neigt, («Wenn sich stille der Tag neigt», literalmente «Cuando declina quieto el día»). En cambio, nuestro autor opta por una construcción de infinitivo: «Al extinguirse quietamente el día». En consecuencia, el verbo queda neutralizado respecto de las marcas de persona y, sobre todo, de tiempo. De este modo, lo que es paradoja temporal en el verso de Trakl, pues el

${ }^{19}$ En alemán la pasiva se forma con el verbo auxiliar werden («llegar a ser»), que en castellano se traduce por la perífrasis pasiva ser + participio. No obstante, en alemán existe otro modo de construir la pasiva, cuya finalidad es la de incidir más en el resultado o el estado derivado de un proceso que en el propio proceso. Dicha construcción consiste en emplear como verbo auxiliar, en lugar de werden, el verbo sein (ser o estar), y que en castellano se traduce por estar + participio.

${ }^{20}$ Werden, como ya quedó dicho antes, sirve en alemán para expresar un cambio de estado efectivo. 
dinamismo temporal de la construcción sintáctica y del verbo quedan contrarrestados por el estatismo que imprime a toda la oración, con su posición intersticial en el verso, stille (quieto), en Valente se concentra en la forma verbal, ya que el significado de este, 'extinguir', remite al proceso de desaparición y el empleo del infinitivo remite a la neutralización del tiempo, o para ser más precisos, remite al no-tiempo. Desde este punto de vista, la presencia del adverbio sería superflua en el verso valenteano; sin embargo, al mantenerlo también en el centro del verso parece querer realizar un guiño al acierto estilístico logrado por el poeta austríaco.

Al principio del análisis, se hacía mención a que el poema de Mandorla era, en cuanto al cuerpo del texto, una versión lingüísticamente bastante fiel del poema «Die Sonne»; y se decía también que el distanciamiento entre el texto del gallego y del austríaco se producía en el contorno del texto. En efecto, «Versión de Trakl-Webern» solo se aleja del poema referido por el hecho nada superfluo y sí muy significativo de poseer otro título y una cita inicial. La elección de título tiene un sentido claro por lo explicado en las páginas anteriores: el poema es una versión de Trakl. Ahora bien, no hay en el cuerpo del texto, en apariencia, ningún elemento que remita a la otra figura referida en el título. Solo la nota previa dispuesta tras el título, que convoca en la lectura el ámbito de lo musical — «Para voz y cuatro instrumentos»- justificaría la referencia al compositor, también austríaco, Anton Webern. Esta referencia, sin embargo, nos sitúa en la pista de que, en realidad, el poema no es traducción del texto de Trakl, sino versión de la pieza musical del compositor que, a su vez, había elegido seis poemas de su compatriota (entre las cuales estaba «Die Sonne») para crear otras tantas canciones. De este modo, el título que pone el autor gallego a su versión de «Die Sonne» convierte dicha traducción, al sobresignificarla con la referencia musical a Webern, en creación poética que, simultáneamente, es traducción de un texto ajeno y versión poética de la composición musical que parte de ese mismo texto.

\section{LA TRADUCCIÓN COMO RECONOCIMIENTO: LAS LECTURAS DE PAUl CELAN}

La importancia que cobra la lectura de la obra poética en alemán del poeta rumano Paul Celan ha sido ya señalada por diversos críticos y el propio José Ángel Valente da testimonio de la generadora fuerza poética que supuso para él el encuentro con la poesía del autor rumano al tomar de él el título de su poemario de 1982 y al incorporar citas y referencias a este en varios textos de su último periodo creativo. Es más, muchos de los conceptos clave que desarrolla el autor de Material memoria en este periodo tienen en Celan la misma importancia y paralelo valor poético ${ }^{21}$.

\footnotetext{
${ }^{21}$ Como resume Martín Gijón (2011: 125), Jonathan Mayhew señala que la obra de Celan ayuda a definir un nuevo modelo de diálogo con el lector que reconocería la radical dife-
} 
No es arriesgado pensar, en este sentido, que la lectura que realiza Valente de Paul Celan le reporta una serie de imágenes que le permiten desarrollar y reafirmar el pensamiento poético-estético que desde sus inicios llevaba elaborando $^{22}$. Asimismo, la lectura en profundidad que implica la traducción de los poemas alemanes del rumano suponen un ejemplo vivencial de la tensión máxima a la que se puede llevar al lenguaje para potenciar su capacidad expresiva, pues Celan opera sobre el alemán un retorcimiento lingüístico similar al que realiza César Vallejo en Trilce sobre el castellano. También en el plano lingüístico, conviene señalar la convergencia de las actitudes poéticas de ambos autores, pues tanto Celan como Valente, aunque por diferente motivo, se encontraron con la paradoja de tener que desarrollar su poesía en una lengua que había sufrido un vaciamiento de su sentido y, por tanto, una desnaturalización de su uso original ${ }^{23}$. Y así lo destaca en su ensayo «Bajo un cielo sombrío»: «La voz de Paul Celan ha bajado a la noche, ha descendido las infinitas escalas de la sombra (...) y ha engendrado en ellas una palabra nueva (...) Palabra, Verbo. Para habitar de nuevo entre nosotros» (Valente, 2008: 714).

Por todo ello, cuando nuestro autor, recorrida ya la mitad de su trayectoria poética, se encuentra con la obra de Paul Celan no puede hacer otra cosa más que reconocerse en su poesía y la lectura y la traducción de su obra se ofrece a los ojos del gallego como diálogo de la que este extrae una experiencia de ahondamiento en su propia obra. Así, lo expresa en uno de los textos liminares que preceden a la edición de las versiones:

DAR por cierto el conocimiento del otro es ignorar que este presunto conocimiento es una mera proyección de nuestro yo. Suprimida esa proyección ocultante, el otro sólo puede ser percibido como esencialmente desconocido: la faz misteriosa del otro. Y, también, sólo en la medida en que es percibido como misterio, puede el otro ofrecérsenos como fuente posible del conocer y del amar (Valente, 2002: 237).

Esta visión de la traducción como un entablar diálogo con el otro, que, en su extremo, revierte sobre sí mismo, coincide con lo afirmado acerca de su concepto de traducción en una entrevista concedida a la revista Archipiélago:

rencia del otro y con ello las dificultades de llegar al lector (2009: 79 y ss.). Apunta también el crítico estadounidense a un entroncamiento común con la tradición heideggeriana como contexto para la conexión entre ambos poetas (2009: 78). Y, por último, Valente vería en Celan un modelo natural en su lucha por reconciliar historicidad con autonomía poética, según Mayhew (2009: 85).

${ }^{22}$ Tal es el caso de la rentabilidad del símbolo de la mandorla, que Valente toma del poema de título homónimo recogido en Die Niemandrose (La rosa de nadie) de Paul Celan.

${ }^{23} \mathrm{El}$ influjo negativo que la retórica nazi ejerció sobre la lengua alemana (vid. Steiner, 2002: 123-140) se suma, en el caso de Celan, a su experiencia personal y a su condición de judío: la lengua que, como poeta, emplea para crear era en su infancia y juventud la lengua del odio, del miedo y, en definitiva, de la destrucción de su identidad cultural.

Con menos dramatismo, pero con igual compromiso, Valente considera que hereda un castellano que necesita ser depurado de los condicionantes negativos que las generaciones precedentes habían introducido en su uso. 
La traducción tiene una importancia sustancial, y en ella está (...) el [hecho] de que necesito incorporarme a un poeta, incorporar la sustancia del poeta, meterme dentro de su voz, y hablar con ella. Es lo que me ha pasado con Paul Celan (PérezUgena, 1999: 56).

En «Antecomienzo»Valente incide en la experiencia lingüística que conlleva el ejercicio de la traducción. El proceso de identificación al que hace referencia en el fragmento anterior, ese meterse en la voz del otro, implica también vivir la carnalidad de la lengua de origen, en este caso, el alemán. Como ya fue señalado antes, el encuentro del poeta ourensano con el alemán se produce en un contexto y a un nivel diferente que en los casos del inglés y del francés (en tanto que fueron lenguas vehiculares y con las que convivió en sus estancias en el extranjero). El alemán, ante los ojos del poeta gallego, es una lengua totalmente nueva, aprendida. Es una lengua con la que la experiencia vital es eminentemente a través de la escritura. Sin embargo y de modo paradójico, esa experiencia por medio de la lectura de la poesía de Paul Celan la siente muy próxima de su experiencia vital, «porque», afirma Valente en la entrevista, «ha estado vinculado a situaciones mías de extrema gravedad» (Pérez-Ugena, 1999: 56). Del mismo modo, considera que el contacto con esa lengua nueva lo obliga a volver a aprender a escribir. De ahí que afirme en «Antecomienzo»: «Las presentes versiones son resultado breve - fecundamente frustrado- de un largo período de frecuentación de un lenguaje nuevo» (Valente, 2002: 233. La cursiva es nuestra).

Ese aprendizaje lingüístico al que hace referencia le permite experimentar los límites del lenguaje propio y concebir nuevos espacios de expresión concebibles solo a partir del contacto con una lengua desconocida ${ }^{24}$. Por ese motivo, el costoso trabajo de familiarización con el alemán y, sobre todo, con el alemán de la poesía de Celan, le supuso la apertura a nuevos ámbitos de expresión y, en paralelo, el abandono de caminos ya gastados del castellano, «de una paralela desfrecuentación de lenguajes gastados o vacíos» (Valente, 2002: 233). La traducción revierte, así, de modo positivo sobre su palabra poética en un acto de refundación o nueva depuración hacia la esencia de lo poético que supone un «ir hacia algún lugar aún nunca hallado, hacia el otro, hacia un tú invocable» (Valente, 2002: 233). Estas palabras finales de «Antecomienzo» son una descripción exacta de la escritura poética que desarrolla a partir de El fulgor (1984), en paralelo con la labor de traducción de la poesía de Paul Celan.

${ }^{24} \ll(\ldots)$ teño dito que cada lingua permite dicir a un cousas que outra lingua no lle permite dicir» (Romaní, 2001: 425).

Una enunciación similar a esta idea la encontramos en Walter Benjamin quien habla, al respecto del difícil trasvase entre dos lenguas, de que en la traducción se «ha de experimentar de manera especial la maduración de la palabra extranjera, siguiendo los dolores del alumbramiento en la propia lengua»(Benjamin, 1971: 132-133). 
Valente valora las versiones que realiza del poeta rumano no en una dimensión de acierto en la traducción — «En general mis traducciones han sido bien aceptadas: no puedo calificarlas de precisas o buenas»- sino en un plano expresivo de trasposición: «son poemas vivientes de Celan en castellano» (Pérez-Ugena, 1999: 56). Esta expresión nos pone sobre la pista de cómo se enfrenta a la tarea de traducir a Celan. Es, para Valente, la experimentación personal de la alteridad creativa. No considera que sea el autor de sus versiones sino que entiende que en el intento de apropiarse de la voz de Celan el resultado ha sido el inverso: es Celan quien lo utiliza para expresarse en castellano.

Por esta razón, a pesar de lo que afirma, las versiones en castellano de los poemas de Paul Celan reproducen con casi total precisión el texto alemán ${ }^{25}$, como ocurre con «Corona» o «Todesfuge», pues lo dicho en el original por Celan se correspondería con exactitud con lo que Valente diría si fuera él el autor del texto. Solo se produce una distancia con el texto alemán cuando no hay correspondencia unívoca entre lo dicho en alemán y lo que se puede decir en castellano o cuando, por motivos gramaticales o léxicos, es imposible encontrar una fórmula similar. Es lo que sucede con la versión del poema «Mandorla» ${ }^{26}$.

El poema de Paul Celan ${ }^{27}$ asienta la fuerza del sentido poético de las imágenes en el empleo reiterativo del verbo stehen, de gran rentabilidad semántica en alemán pues, en función de la estructura gramatical, asume diferentes significados. La base semántica de esta lexía remite a una posición física pre-

${ }^{25}$ En términos similares se expresa Martín Gijón: «Por norma general, Valente sigue en sus traducciones de Celan la mayor fidelidad posible, en todos los niveles, comenzando por la prosodia y la sintaxis». De hecho, asegura unas líneas más abajo, «Valente sigue siempre que puede (...) la sintaxis original, frente a otros traductores» (2011: 127).

En cuanto a la proximidad entre original alemán y versión alemana, coincidimos con este autor en rechazar la consideración de Jaime Siles de que las versiones sean «acaso excesivamente literales» (1994: 9).

${ }^{26}$ El texto de la versión es el siguiente:

En la almendra - ¿qué hay en la almendra? / La Nada. / La Nada está en la almendra. / Allí está, está. // En la Nada — ¿quién está? El Rey. / Allí está, está. // Bucle de judío, no llegarás al gris. // Y tu ojo — ¿dónde está tu ojo? / Tu ojo está frente a la almendra. / Tu ojo está frente a la almendra. / Tu ojo frente a la Nada está. / Apoya al rey. / Así está, está. // Bucle de hombre, no llegarás al gris. / Vacía almendra, azul real (Valente, 2002: 257).

${ }^{27}$ El texto original de Paul Celan es el siguiente: MANDORLA /// In der Mandel — was steht in der Mandel? / Das Nichts. / Es steht das Nichts in der Mandel. / Da steht es und steht. // Im Nichts - wer steht da? Der König / Da steht der König, der König. / Da steht er und steht. // Judenlocke, wirst nicht grau. / Und dein Aug — wohin steht dein Auge? / Dein Aug steht der Mandel entgegen. / Dein Aug, dem Nichts stehts entgegen. / Es steht zum König. / So steht es und steht. // Menschenlocke, wirst nicht grau. Leere Mandel, königsblau (Celan, 1999: 173). 
dominantemente vertical; así, asociado al nexo locativo in + dativo (que indica posición dentro de un lugar cerrado), se puede traducir como 'estar de pie dentro de', 'hallarse', 'encontrarse en'. Por eso, la primera pregunta del poema de Celan «was steht in der Mandel?», puede entenderse como un cuestionamiento acerca de lo que contiene la almendra; de ahí, la respuesta: «Das Nichts» (la Nada). Por esa razón, Valente decide traducir este primer steht como «haber»: «iqué hay en la almendra?».

Una vez identificado el ser que habita el seno de la almendra, ya no interesa seguir incidiendo en el contenido. El foco de interés poético se traslada de la almendra como receptáculo a la almendra como espacio de aparición y, por tanto, el centro de la imagen poética ya no es la almendra, sino la nada, esto es, el ser que contiene. Así, el sentido de stehen en el tercer verso ya está más próximo en castellano al sentido de estar que al de haber. Por ello, opta por traducir «Es steht das Nichts in der Mandel» por: «La Nada está en la almendra».

Esa transición del espacio (la almendra), a la aparición del Ser que lo habita (la Nada) queda corroborado en el quinto verso. Allí la función de sujeto gramatical del verbo stehen, que anteriormente había sido asumida, en primer lugar, por el interrogativo was $^{28}$ —pronombre para objetos inanimados- y, después, por das Nichts — sustantivo abstracto y, en consecuencia, ser no animado-, ahora recae en el interrogativo de persona wer. Desde el ente inanimado al individuo pasando por el ser informe; la predicación gradativa que en alemán tiene un único centro verbal, la palabra stehen, carece de paralelo expresivo en castellano. Por eso, Valente se ve en la disyuntiva entre mantener el juego lingüístico o el sentido profundo de la imagen. Como se puede ver, opta por lo último y, así, se ve en la obligación de traducir stehen por haber y estar ${ }^{29}$.

En el verso 12 stehen, al ir acompañado de la preposición $z u^{30}$, significa literalmente «estar para alguien», es decir, «estar de parte de» o «apoyar a alguien», que es la solución que escoge Valente. Por otro lado, los correlatos castellanos que el poeta ourensano escoge para traducir los diferentes stehen del poema original guardan relación con los valores gramaticales del verbo

${ }^{28}$ El interrogativo alemán was, cuyo valor semántico y sintáctico es similar al qué castellano, en esta oración asume la función de sujeto pero no la de agente, pues stehen refiere un estado y no un proceso. De ahí que, aunque el verbo no es impersonal desde el punto de vista sintáctico sí lo es desde el punto de vista semántico y, por eso, la traducción por la forma impersonal del verbo haber es, en este sentido, un acierto lingüístico.

${ }^{29}$ José Luis Reina Palazón, en la edición de las obras completas de Celan publicadas por Trotta, intenta mantener la unipresencialidad del verbo en el poema. Así, stehen es traducido siempre por la forma de pasiva refleja se tiene. Cfr. Celan (1999: 173).

${ }^{30} \mathrm{Zu}$ sirve para apuntar hacia el destino último de un proceso o estado: lugar, en caso de que se emplee con verbos de movimiento; finalidad, objetivo, en caso de que el verbo exprese una acción. 
alemán, que, además de poder significar diferentes cosas dependiendo de la estructura sintáctica que rija en la oración, en ocasiones, puede no existir en castellano. Tal es el caso del verso 11.

La oración, en una estructura sintáctica normativa, sería: «Dein Aug steht dem Nichts entgegen» («Tu ojo está frente a la Nada»). Al tematizar el sujeto mediante su desplazamiento fuera de la oración y su separación de esta por la presencia de la coma, deja a la construcción sin sujeto semántico y se convierte, así, en una oración impersonal ${ }^{31}$. Es claro que la mayor flexibilidad de la sintaxis castellana en cuanto al ordenamiento de los constituyentes hace que, aunque también se tematizase el sujeto, no devendría por lógica gramatical una impersonalización de la oración; pues si tradujera «Tu ojo, frente a la Nada está» el sintagma mantendría sus valores de sujeto gramatical y sujeto semántico. Por eso, puesto que es imposible encontrar una equivalencia en castellano que vehicule todas las implicaciones gramaticales y de sentido del verso de Celan, el poeta gallego opta por marcar por medio de un hipérbaton la operación realizada por el autor rumano en su poema: «Tu ojo frente a la Nada está».

\section{LA TRADUCCIÓN COMO AUTOLECTURA: LAS VERSIONES DE EDMOND JABÈS}

Si en la lectura y traducción de Paul Celan José Ángel Valente experimenta una refundación de su escritura poética al incorporar la estética del rumano a su pensamiento poético y, así, hacer evolucionar su poesía hacia un punto extremo de su propuesta estética, en la frecuentación de la poesía de Edmond Jabès experimenta una relectura de su obra anterior que reaviva el sentido de los elementos que configuraban aquella escritura, resignificándolos. Es lo que Sánchez Robayna define como influencia retrospectiva, «una influencia que le hacía ver de otra manera determinados aspectos de su propia obra - o verlos, incluso, por primera vez-, considerados a la luz de la peculiar simbología jabesiana» (2006: 52). De este modo, como le sucede con Celan, Valente experimenta en la traducción una identificación personal con lo traducido, un reconocimiento de la voz propia en la voz del otro. Así lo refiere el propio autor en el ensayo que dedica al poeta francófono:

El contacto con la poesía de Jabès no determina propiamente las líneas fundamentales de mi escritura subsiguiente. Determina algo para mí mucho más decisivo: una nueva perspectiva de lo que yo había escrito hasta ese momento. Hace el

\footnotetext{
${ }^{31} \mathrm{La} \ll \mathrm{S} » \mathrm{de}$ la forma verbal stehts, frecuente en poesía y en algunas hablas dialectales del alemán, remite al pronombre es. De tal modo, la construcción sería es steht, donde es puede interpretarse como pronombre que se refiere a Dein Aug, pero también como marca de impersonalidad, al igual que sucede en las construcciones impersonales con verbo meteorológico.
} 
encuentro con Jabès que yo me reconozca a mí mismo, me dota de una identidad, de una estirpe, de una ascendencia (Valente, 2008: 663).

En Edmond Jabès Valente se reencuentra, como señala Sánchez Robayna, con los símbolos de la mística: el desierto, la noche, el fuego, la nada ${ }^{32}$. Así, la escritura del ensayo «La memoria del fuego», recogido en Variaciones sobre el pájaro y la red, se apoya en la lectura de textos del poeta franco-egipcio. Pero, también, como ocurría con Paul Celan, la figura de Jabès supone para nuestro poeta la encarnación de una serie de elementos hacia los que tendía su pensamiento poético: el exilio, la mística judía, el silencio ${ }^{33}$.

Esta confluencia en o desde el origen marca, como en el caso de Paul Celan, la labor valentena de traducción. Al igual que le sucede con el poeta de habla alemana, las traducciones que realiza del francés el autor ourensano se caracterizan por una casi total equivalencia entre texto original y traducción, como si las palabras de Jabès no requiriesen alteración alguna para ser sentidas como propias. De este modo, la relevancia de las versiones de Edmond Jabès no reside tanto en el trabajo de trasposición lingüística como en el de la lectura selectiva que hace Valente de su obra, en busca de fragmentos con los que identificarse. Así, extrae de su contexto diferentes textos de libros de Edmond Jabès y configura con ellos una lectura esencial del universo literario del escritor judío, agrupada en cuatro secciones que titula del siguiente modo: «Jabès por Jabès», «Lengua fuente lengua blanco» ${ }^{34}$, «Confesiones»y «Fragmentos» ${ }^{35}$.

La tarea de reescritura de la versión valenteana de los textos de Edmond Jabès consiste en extraer del discurso original fragmentos con cierta unidad de sentido y asignarles un título, inexistente en el original, que los convierte en unidades textuales llenas de sentido por sí misma; es decir, los fragmentos en el original se convierten con la intervención valenteana en texto autónomo, gracias a la acción interpretadora y recreadora que supone la lectura implícita que hay detrás de la traducción. La presencia de título incide, pues, en el carácter textual del fragmento sin que este pierda, paradójicamente, su condición fragmentaria.

${ }^{32}$ Cfr. Sánchez Robayna (2006: 52).

${ }^{33}$ Cfr. el ya citado ensayo «La memoria del fuego», «Sobre la unidad de la palabra escindida», y sobre todo «Jabès o la inminencia» y «Edmond Jabès: judaísmo e incertidumbre».

${ }^{34}$ El primer grupo de versiones consiste en una serie de fragmentos extraídos del libro Du désert au livre. Entretiens avec Marcel Cohen que en la traducción que realiza Valente se constituyen en introducción a la figura y la simbología literaria del poeta francés. A este conjunto se suma, al final, un poema «Très tôt...», extraído de Livre du partage.

De ese mismo libro traduce «Langue source langue cible» (con el espacio tipográfico en blanco entre los dos sintagmas), que se constituye en la versión valenteana en el grupo que titula «Lengua fuente lengua blanco».

Estas versiones fueron publicadas, por primera vez, por Valente en 1988 en Syntaxis. 1617, pp. 4-7 y 8-14. Cfr. apéndice a Valente (2002: 427 y 431). 
De este modo, la lectura esencializadora de la obra de Edmond Jabès actúa en el nivel del libro: esa unidad material queda, en la lectura interpretante de Valente, condensada en una serie de fragmentos, de especial interés o significación para el traductor. Pero también se produce la selección dentro del propio fragmento, pues, como sucede en la versión titulada «El desierto», no es infrecuente encontrar saltos en la lectura signados en el texto por medio de puntos suspensivos entre corchetes. Así pues, la traducción que realiza sobre la obra de Edmond Jabès se mueve por el interés de la autolectura y se materializa en una intervención sobre el original por esencialización o concentración. La versión que ofrece Valente se muestra, así, como lugar de comunión entre el lector-traductor y el autor-creador.

Como consecuencia de esta actitud resignificadora, la pura trasposición lingüística al castellano de los fragmentos de Edmond Jabès da lugar a una creación textual que dialoga ya no tanto con el original como con los textos del propio traductor. La versión titulada «El desierto», por ejemplo, se sitúa en un espacio que, por un lado, en tanto que traducción remite al original jabesiano y, por el otro, en tanto que autolectura remite al poema «Serán cenizas...», de $A$ modo de esperanza ${ }^{36}$, del que se vuelve comentario o glosa: «El desierto fue para mí el lugar privilegiado de mi despersonalización» (Valente, 2002: 321).

En idéntica situación nos encontramos con la versión que lleva por título «Escritura, palabra», donde el inicio — «No es posible escribir sin hacer callar primero las palabras que nos agitan» (Valente, 2002: 327)— recuerda a uno de los más importantes aforismos recogidos en Notas de un simulador: «ESCRIBIR por espera, y no desde la locución, sino desde la escucha de lo que las palabras van a decir» (Valente, 2006: 461) ${ }^{37}$. Del mismo modo, el segundo párrafo de la versión se convierte en una sumarización del pensamiento poético que Valente había desarrollado y expuesto años atrás en Las palabras de la tribu: «la inflación verbal — de la que resultan palabras privadas de peso- a la que estamos diariamente confrontados trata también de imponer silencio al escritor» (Valente, 2002: 335).

Otro tanto se puede decir de «Lengua fuente lengua blanco», en cuyas líneas se pueden leer fragmentos sobre el silencio y su relación con la pala-

${ }^{35} \mathrm{El}$ tercer grupo lo configuran nuevas versiones de otros tantos fragmentos extraídos de Du désert au livre. Entretiens avec Marcel Cohen. Y el cuarto grupo son textos entresacados para su traducción de Un Etranger avec, sous le bras, un livre de petit format. Este segundo conjunto de traducciones aparecen por primera vez en 1991 en El europeo. 29, p. 99. Cfr. apéndice a Valente (2002: 427 y 431).

${ }^{36}$ Cfr. con el primer poema de Valente: «Cruzo un desierto y su secreta / desolación sin nombre. / El corazón tiene la sequedad de la piedra / y los estallidos nocturnos / de su materia o de su nada» (Valente, 2006: 69).

${ }^{37}$ En Diario anónimo aparece fechada la primera versión de este texto: 5 de junio de 1983 (2011: 225). 
bra que bien podrían pasar por afirmaciones del propio Valente y que, de algún modo, entran en diálogo con sus textos. Así, «Pensar el silencio es, de algún modo, hacerlo audible. / El silencio no es debilidad del lenguaje. / Es, por el contrario, fuerza» (Valente, 2002: 331) recuerda al fragmento «Poética: arte de la composición del silencio. Un poema no existe si no se oye, antes que su palabra, su silencio» (Valente, 2006: 388), de «Cinco fragmentos para Antoni Tàpies». Del mismo modo, los versos jabesianos «Más que al sentido apégate al silencio que ha modelado la palabra. / Aprenderás más sobre él y sobre ti, siendo tan solo, el uno y el otro, escucha» (Valente, 2002: 331) podrían considerarse comentario amplificativo del aforismo «SE ESCRIBE por pasividad, por escucha, por atención extrema de todos los sentidos a lo que las palabras acaso van a decir» (Valente, 2008: 460), de Notas de un simulador. Así también, podemos considerar que el aserto «La lengua escrita es una lengua que está, a la vez, dentro y fuera de la lengua» (Valente, 2002: 337) del escritor francés parece la sumarización del discurso hermenéutico que Valente construye sobre el lenguaje místico en La piedra y el centro y Variaciones sobre el pájaro y la red, que lo lleva a enunciar su teoría de la palabra poética como estado de máxima tensión en el que se produce la suspensión del lenguaje en su instrumentalidad ${ }^{38}$.

\section{LA TRADUCCIÓN COMO COMUNIÓN}

Creemos que del análisis de las calas realizadas en el corpus de Cuaderno de versiones se desprende una visión clara de su concepto de traducción como reescritura creativa, así como del modo en que enfrenta dicha tarea; de modo que vendríamos a coincidir con lo que Martín Gijón afirma al respecto de las versiones valenteanas de Celan: «la traducción, entendida como la hizo Valente, supondría el ejemplo más profundo de lectura interpretativa» (2011: 143). Y se desprende, también, de nuestro análisis una imagen clara de que para Valente no hay diferencia esencial entre traducción y creación. Es más, el poeta gallego parece dejar claro que la experiencia de la traducción en tanto que experiencia vívida de una alteridad interior (ya sea como reescritura, como apropiación, como reconocimiento o como autolectura) reporta a su obra literaria una vía para reconocer su obra en otras obras, para reconocerse en otros autores, para experimentar la certidumbre de una noción cardinal en su pensamiento poético: la experiencia poética es una experiencia desvinculada de la experiencia personal, pero no por ello menos verdadera.

Por eso, entendemos que Valente incide en los textos preliminares a sus versiones varias veces en la sensación de proximidad espiritual que acarrea

\footnotetext{
38 «Mostrar que hay un indecible existente es función máxima de esa palabra que pone en tensión máxima al lenguaje entre el decir y el callar»(Valente, 2008: 309).
} 
la traducción. «¿Inscribo en el molde de la ajena visión mi propio pensamiento?», se pregunta en el texto que precede a sus versiones de dos poemas del poeta alemán Günter Kunert (Valente, 2002: 399). En la traducción Valente experimenta de un modo vivencial la sensación de desaparición de los límites entre la identidad propia y la ajena. O, por ser más exacto, la validez literaria de la traducción le certifica la inutilidad de la oposición yo-otro en el territorio del poema. He ahí que Valente se interrogue acerca de la traducción: « ¿Son las palabras intercambiables si la poesía es testimonio de la misma verdad?» (Valente, 2002: 399).

Esta intercambiabilidad de las palabras de lenguas distintas, esta constatación del parentesco de las lenguas en la traducción de la que hablaba Walter Benjamin (1971: 133) apunta en Valente, acaso, a la experimentación de la liberación del lenguaje preso benjaminiano, la experimentación del contacto con la lengua suprema de Mallarmé, estado desde el cual se accede a la verdad poética en un ámbito en el que se suspende la oposición de sentido entre creación y traducción, entre autor y traductor, la oposición, en definitiva, entre poema original y poema traducido. Cuando la poesía habla, parece decir Valente, la materialidad de la lengua (y aún diría más, la identidad del sujeto en que la poesía habla) poco importa o, por ser más precisos, son accidentales quién y en qué lengua habla cuando se produce una comunión radical de la verdad del poema.

\section{BIBLIOGRAFÍA CITADA}

Benjamin, Walter (1971). «La tarea del traductor», en Walter Benjamin, Angelus novus. H. A. Murena (trad.). Barcelona: Edhasa, pp. 127-143.

Celan, Paul (1999). Obras completas. José Luis Reina Palazón (trad.). Madrid: Trotta.

Fernández González, Vicente (2001). La ciudad de las ideas: sobre la poesía de C. P. Cavafis y sus traducciones castellanas. Madrid: CSIC.

Fernández Rodríguez, Manuel (2004). «A poética da modernidade de Eugenio Montale e a súa relación con José Ángel Valente», Moenia. 10, pp. 73-95.

Fernández Rodríguez, Manuel (2006). «Escrituras como renuncia. As traducións de José Ángel Valente». Viceversa. 11, pp. 11-22.

Gimferrer, Pere (1964). «Cavafis entre nosotros», Ínsula. 214, p. 3.

Martín Gijón, Mario (2011). «»Un demorado diálogo». Las versiones de Paul Celan por José Ángel Valente y los límites de la traducción», Letras de Deusto. 41, 133, pp. 123-144.

Mayhew, Jonathan (2009). «Valente's Lectura de Paul Celan. Translation and the heideggerian tradition in Spain», Diacritics. 34, 3-4, pp. 73-89.

Paz, Octavio (1990). Traducción, literatura y literalidad. Barcelona: Seix Barral.

Pérez-Ugena, Julio (1999). «El jeroglífico y la libertad. Entrevista a José Ángel Valente». Archipiélago. 37, pp. 55-61.

Pérez-Ugena, Julio (2003). «Muerte, piedad y memoria: Il tuffatore de Paestum en las obras de Eugenio Montale y de José Ángel Valente», Criticón. 87-88-89, pp. 661-678.

Rodríguez Fer, Claudio (2002). «Introducción», en José Ángel Valente, Cuaderno de versiones. Barcelona: Galaxia Gutenberg \& Círculo de Lectores, pp. 7-37. 
Romaní, Ana (2001). «Entrevista a José Ángel Valente», Grial. XXXIX, 151, pp. 421-427. Sánchez Robayna, Andrés (2006). «Introducción», en José Ángel Valente, Obras completas, I. Poesía y prosa. Barcelona: Galaxia Gutenberg \& Círculo de Lectores, pp. 9-55. Siles, Jaime (1994). «Lectura de Paul Celan», ABC literario. 15 de abril, p. 9.

Steiner, George (2000). «El milagro hueco», en Lenguaje y silencio. Miguel Ultorio (trad.). Barcelona: Gedisa, pp. 123-140.

Valente, José Ángel (2002). Cuaderno de versiones. Barcelona: Galaxia Gutenberg \& Círculo de Lectores.

Valente, José Ángel (2006). Poesía y prosa. Obras completas, I. Barcelona: Galaxia Gutenberg \& Círculo de Lectores.

Valente, José Ángel (2008). Ensayo. Obras completas, II. Barcelona: Galaxia Gutenberg \& Círculo de Lectores.

Valente, José Ángel (2011). Diario anónimo. Barcelona: Galaxia Gutenberg \& Círculo de Lectores.

Fecha de recepción: 24 de octubre de 2012.

Fecha de aceptación: 22 de mayo de 2013. 